\title{
Association between health behaviors and mood disorders among the elderly: a community-based cohort study
}

Tzu-Jung Tseng ${ }^{1 \dagger}$, Yi-Syuan $\mathrm{Wu}^{1,2+}$, Jia-Hong Tang ${ }^{3}$, Yen-Hui Chiu ${ }^{4}$, Yu-Ting Lee ${ }^{1}$, I-Chun Fan ${ }^{1,5}$ and Ta-Chien Chan ${ }^{1,6^{*}}$ (D)

\begin{abstract}
Background: According to a WHO report, nearly 15\% of adults aged 60 and over suffer from a mental disorder, constituting $6.6 \%$ of the total disability for this age group. Taipei City faces rapid transformation towards an aging society, with the proportion of elderly in the total population rising from 12\% in 2008 to 16\% in 2016. The aim of this study is to identify the prevalence of mental disorders among the elderly in Taipei City and to elucidate risk factors contributing to mental disorders.

Methods: The elderly health examination database was obtained from the Department of Health, Taipei City government, from 2005 to 2012. A total of 86,061 people underwent publicly funded health examinations, with 348,067 visits. Each year, there are around 43,000 elderly persons in Taipei City using this service. We used a mental health questionnaire including five questions to estimated relative risks among potential risk factors with the generalized estimating equations (GEE) model to measure the mental health status of the elderly. Mood disorders were measured with the Brief Symptom Rating Scale (BSRS-5) questionnaire. Age, education level, gender, marital status, living alone, drinking milk, eating vegetables and fruits, long-term medication, smoking status, frequency of alcohol consumption, frequency of physical activity, BMI, and number of chronic diseases were included as covariates.
\end{abstract}

Results: The results show that being male (odds ratio (OR) $0.57 ; 95 \% \mathrm{Cl}=0.56,0.59$ ), higher education (OR 0.88; $95 \% \mathrm{Cl}=0.82,0.95)$, no long-term medication $(\mathrm{OR} 0.57 ; 95 \% \mathrm{Cl}=0.56,0.58)$, and exercising three or more times per week (OR 0.94; $95 \% \mathrm{Cl}=0.91,0.98)$ were all positively correlated with better emotional status. However, being divorced $(\mathrm{OR}=1.22,95 \% \mathrm{Cl}=1.09,1.36)$, not drinking milk $(\mathrm{OR}=1.12,95 \% \mathrm{Cl}=1.09,1.14)$, not eating enough vegetables and fruits every day $(\mathrm{OR}=1.78,95 \% \mathrm{Cl}=1.73,1.83)$, daily smoking $(\mathrm{OR}=1.15,95 \% \mathrm{Cl}=1.01,1.32)$, and having more chronic diseases $(\mathrm{OR}=1.02,95 \% \mathrm{Cl}=1.01$, 1.03) were all correlated with poor mental status among the elderly.

Conclusions: The findings of this research can both estimate the prevalence of mood disorders at the community level, and identify risk factors of mood disorders at the personal level.

Keywords: Elderly health examination database, Socio-economic status, Health behaviors, Mental health, Mood disorders

\footnotetext{
* Correspondence: dachianpig@gmail.com

${ }^{\dagger}$ Tzu-Jung Tseng and Yi-Syuan Wu contributed equally to this work.

${ }^{1}$ Research Center for Humanities and Social Sciences, Academia Sinica, Taipei,

Taiwan

${ }^{6}$ Institute of Public Health, School of Medicine, National Yang-Ming

University, Taipei, Taiwan

Full list of author information is available at the end of the article
}

(c) The Author(s). 2019 Open Access This article is distributed under the terms of the Creative Commons Attribution 4.0 International License (http://creativecommons.org/licenses/by/4.0/), which permits unrestricted use, distribution, and reproduction in any medium, provided you give appropriate credit to the original author(s) and the source, provide a link to the Creative Commons license, and indicate if changes were made. The Creative Commons Public Domain Dedication waiver (http://creativecommons.org/publicdomain/zero/1.0/) applies to the data made available in this article, unless otherwise stated. 


\section{Background}

The ageing population is growing rapidly. The World Health Organization (WHO) estimated that the proportion of the elderly population in the world will jump from 12 to $22 \%$ between 2015 and 2050 . Over $20 \%$ of elderly persons have suffered from mental or neurological disorders [1]. In addition, several community-based cohort studies have found that mood disorders are an important risk factor for suicide in the elderly, and significantly reduce the quality of life and increase disease burden [2]. According to a National Health Service (NHS) report in the UK, half of adults (7.7million) aged 55 and over have experienced common mental health problems [3]. Therefore, the UK government established a plan to help the elderly through general practitioners (GP) and a complete community care system to detect the signs of mood disorders early $[4,5]$. In the United States, $18.29 \%$ of adults (nearly 43.7 million Americans) struggle with mental health problems annually [6]. Additionally, the proportion of older adults who experience mood disorders is 6.8\% [7]. A study with a sample of 3142 older men and women (aged 65-84 years) indicated that one in two individuals had experienced mental disorders in their lifetime, one in three within the past year, and nearly one in four currently had a mental disorder [8]. In Asia, including the elderly, about $8.8 \%$ of people aged above 20 suffer mood disorders in Japan [9]. With a growing proportion of older adults in Japan, the number of older adult patients ( $\geq 65$ years old) with mood or anxiety disorders has also been increasing, reaching 340,000 in 2014 [10]. In the context of this rapid population aging, there is a growing interest in promoting healthy aging, including the mental health of the elderly.

There are multiple risk factors for mental health problems in the elderly, such as demographic characteristics, e.g., being female, unmarried, living alone, or children not being around [11]. Socio-economic indicators such as low household income [11], low education level [12], and other individual characteristics like chronic diseases, lack of participation in community sports or physical activities [13], physical illness, and poor health status are all associated with higher rates of mood disorders [14]. In addition, one study found that regular physical activity in midlife is significantly associated with reduced depressive symptoms 25 years later [15]. Previous research also indicated that physical activity is a protective factor for mental health in older adults [16]. However, light physical activity, independent of moderate to vigorous physical activity, is associated with fewer depressive symptoms [17]. In summary, the past studies pointed out that being female [11], divorced [11], living alone [11], low education level [12], not doing physical activity $[13,15]$, having chronic diseases, and bad health status are correlated with mood disorder in the elderly [14]. However, the correlation between smoking behavior and mood disorder in the elderly has diverse conclusions in the literature $[18,19]$. Some health behaviors considered in this study such as drinking alcohol, eating vegetables and fruits, and drinking milk are not mentioned in past studies. In addition, this study collected a wide spectrum of the elderly population, including healthy and sick elderly in the communities, and provided the opportunity to identify the changeable behaviors in daily life.

Preventive intervention can reduce the disease burden of mood disorders. Previous studies have indicated that prevention and intervention in the early stages are very effective to reduce severity and prevent secondary disorders, such as degradation of cognitive functions [20]. Sarris and colleagues [21] provide a nexus between public health promotion and clinical treatments, involving the application of environmental and behavioral interventions to enhance physical and mental well-being, calling it "Life Medicine." However, these studies recruited a wide age range of subjects, or focused on the disease of depression itself. As far as we know, there is little information on how to use community health examinations to identify mood disorders or emotional problems in the elderly [18]. In addition, few studies have large samples and discuss health in the elderly in a community with a longitudinal cohort.

In this study, we applied the Taipei City Elderly Health Examination Database for a total of eight years of follow-up data to identify possible risk factors early. The database included not only the basic physical characteristics of the individual, but also variables of healthy behavior, for example, the frequency of smoking, drinking alcohol, frequency of physical activity, and the number of underlying diseases and drug history. The primary objective of this study was to elucidate the potential risk factors associated with mood disorders through using BSRS-5 (5-item Brief Symptom Rating Scale) scores [22]. The second aim of this study was to find risk and protective factors with mood disorders, so as to be able to provide health policy makers suggestions for health education intervention to reduce the risk of mood disorders in the elderly.

\section{Methods}

\section{Ethics}

This study was designed as a retrospective longitudinal cohort study. Every enrolled participant needed to fill out an informed consent form to authorize the Taipei City Government to process health examination data for the research purpose [23]. Data are stored centrally in the Taipei Geriatric Health Examination Database and are de-identified before release. This study was approved by the Institutional Review Board (IRB) on Biomedical Science Research, Academia Sinica (AS-IRB02-104182).

There are two phases for the elderly to join this publicly funded health examination. The essential two criteria are 
age $>=65$ years and having one's registered residence in Taipei City. Phase one is for aborigines, those living alone, low-income households and disabled people. Registration is by phone and the internet during the last week of February each year. Phase two is open to all elderly persons who are eligible for the health examination that register by telephone, internet and on-site registration. All participants can receive the health examination once annually.

\section{Data source}

A study cohort consisting of participants aged 65 and older was obtained from the Taipei Geriatric Health Examination Database. Our study period covered 2005 to 2012. The Taipei City Government provides free annual health examinations for the elderly population of Taipei City. Each year approximately 40,000 to 46,000 people participate in this program, with approximately a 13 to $16 \%$ participation rate $[24,25]$. The examination includes a standardized medical examination and questionnaire that addresses a variety of health-related topics. The health examination database we used here is longitudinal and based on voluntary participation by qualified aged citizens in Taipei City. Our study's purpose is to measure the association between mood disorders and health-related behaviors by repeated measurements, rather than one-shot measurement. Thus, we selected only the participants who came to the health examination program at least two times. Figure 1 shows the overall frequency of the health examination.

\section{Selection of participants}

From 348,067 older adults who participated in the elderly health examination in Taipei City, we enrolled 339,751 elderly individuals with mood disorders data. Those with age less than 65 years old or missing data of education level or marital status were excluded. Finally, we enrolled 315,045 study subjects for further analyses (Fig. 2).

\section{Outcomes}

We applied the measurement from BSRS-5 developed by Lung and others [22] as our study outcome. There are five questions in total and each question is from 0 to 4 points. The total score is thus from 0 to 20 points. The questions are as follows: (1) having trouble falling asleep (insomnia); (2) feeling tense or keyed up (anxiety); (3) feeling annoyed easily or irritated (hostility); (4) feeling low mood (depression); and (5) feeling inferior to others (interpersonal hypersensitivity: inferiority). The participants were asked to rate symptoms on a 5-point scale: 0 , not at all; 1 , a little bit; 2 , moderately; 3 , quite a bit; and 4, extremely, and a total score was calculated for each participant. The total scores were classified into four levels. Total score $>=15$ means severe mood disorder, with professional counseling or psychiatric treatment recommended, between 10 and 14 means moderate mood disorder, between 6 and 9 means mild mood disorder, between 0 and 5 means normal group, and these were coded from 4 to 1 , respectively.

\section{Demographic variables, health behaviors and biochemical data}

The data for this study include responses to a self-report questionnaire containing demographic variables and health behaviors. One past study using the BSRS-5 questionnaire to screen for psychologic disorders in Taiwan

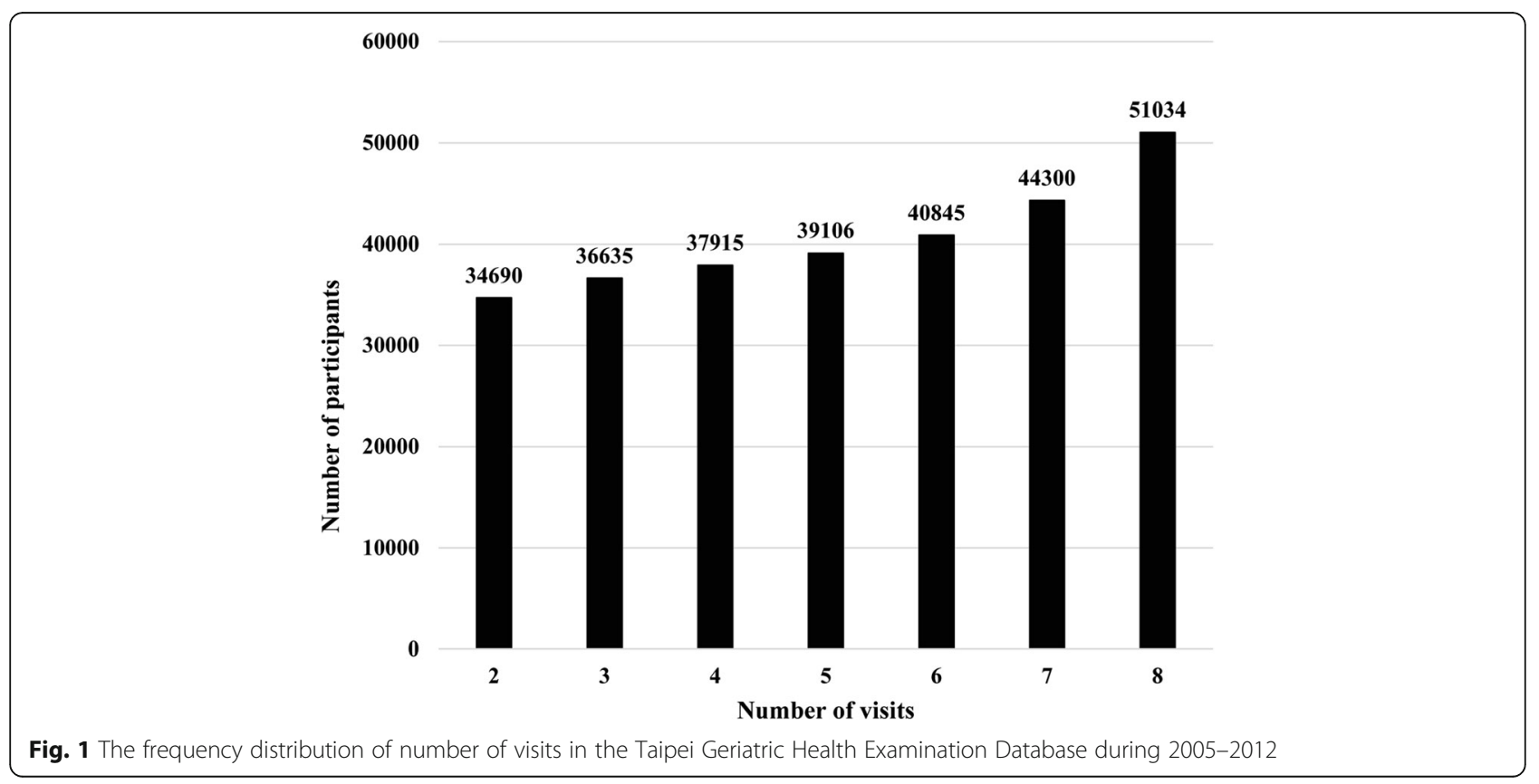


348,067 elderly persons registered in Taipei elderly health examination from 2006 to 2012 .

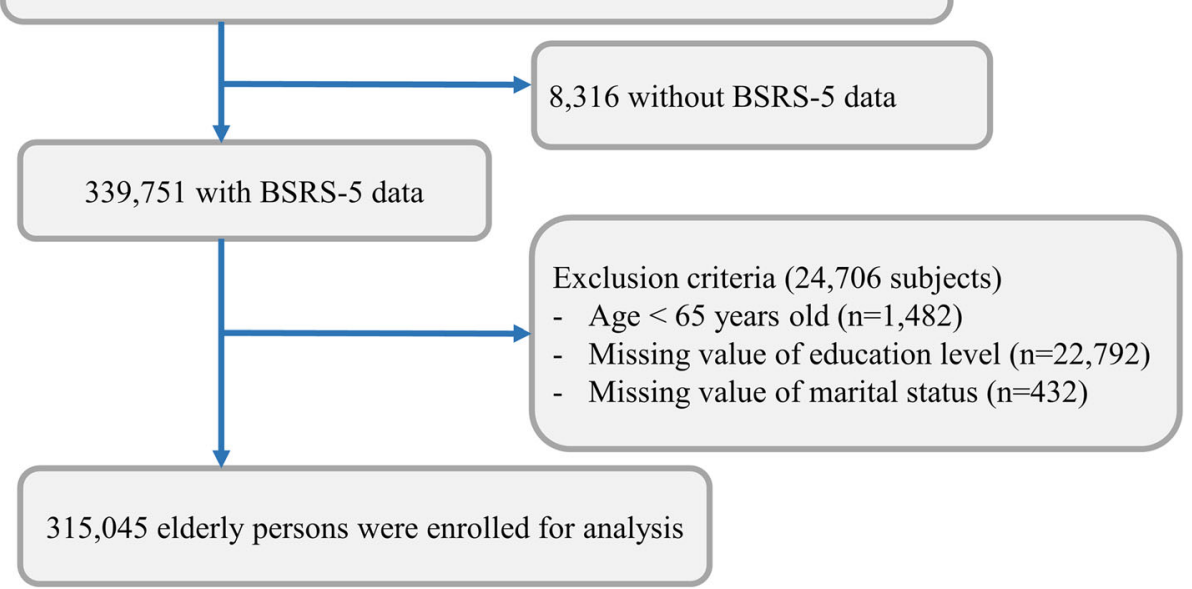

Fig. 2 Flow chart of enrollment of study participants

found that it had good reliability and validity [16]. Demographic information, such as age (in five-year increments starting from 65 years old), gender (male and female), BMI, educational level (illiterate, self-taught, elementary school, junior high and senior high school, vocational school, university, and master's and above), and marital status (married, living together or not; unmarried, widowed, divorced or cohabitating) was collected. For health behaviors, firstly, nutrient data (at least three servings of vegetables and two servings of fruits; and milk drinking), and substance usage (alcohol drinking frequency -- occasionally, daily, or none; and smoking frequency -- after meals, daily or none) were also defined. Secondly, frequency of physical activity (occasional, three to five times per week or even never) was classified. Individual health information was also measured and collected, for example, taking long-term medication or not, number of chronic diseases, and physical and biochemical values (height $(\mathrm{cm})$, weight $(\mathrm{kg})$, systolic and diastolic pressure $(\mathrm{mmHg})$, pulse rate, glucose level $(\mathrm{mg} / \mathrm{dL})$, cholesterol level $(\mathrm{mg} / \mathrm{dL})$, triglycerides $(\mathrm{mg} /$ $\mathrm{dL})$, GOT (U/L), and GPT (U/L)). In this study, we used a two-stage approach to select the potential risk factors including variable selection by logistic regression at the first stage and model fitting by generalized estimating equations (GEE) at the second stage.

\section{Statistical analyses}

Our analysis can be divided into two parts. The first part is to understand the spatio-temporal pattern of mood disorder prevalence in 12 districts of Taipei City. For this, we used the ring map toolbox in ArcGIS 10.2 (Esri Inc., Redlands, CA, USA) [26]. The second part is to identify the risk factors associated with mood disorder.
The Chi-square test of independence was used to determine whether there is a significant relationship between mood disorder and personal characteristic variables. The biochemical difference between those with and without mood disorder was statistically analyzed with one-way analysis of variance (ANOVA). We used logistic regression to select the variables with a significance level at $p$ $<0.05$. To take the within-subject correlation into account, the GEE [27] with a logit link function were conducted for estimating relative risks of the demographic and biochemical factors. All analyses were performed using SPSS version 25.0. Statistical significance was set at $p<0.05$.

\section{Results}

\section{Characteristics of the study population}

Data from 2005 to 2012 on a total of 315,045 elderly persons aged over 65 were included in this study. Figure 3a represents the number of elderly persons taking the health examination each year in 12 districts. Higher numbers used the health examination in Da'an, Songshan and Shilin districts. In addition, the percentage of education status higher than senior high school was also high in Da'an and Songshan districts, but low in Shilin (Fig. 3b). The annual percentages of BSRS-5 levels, including normal (Fig. 3c), mild (Fig. 3d), moderate (Fig. 3e), and severe emotional disorders (Fig. 3f) are depicted in four ring maps. Among our study subjects, a high percentage of mild and moderate emotional disorders is found for those living in Shilin (a northern district) (Fig. 3d, e). Notably, there was an increasing trend in moderate emotional disorders from 2005 to 2012 in Nangang District (a southeastern district) (Fig. 3e). Higher percentages $(\geqq 0.28 \%)$ of elderly persons with serious 

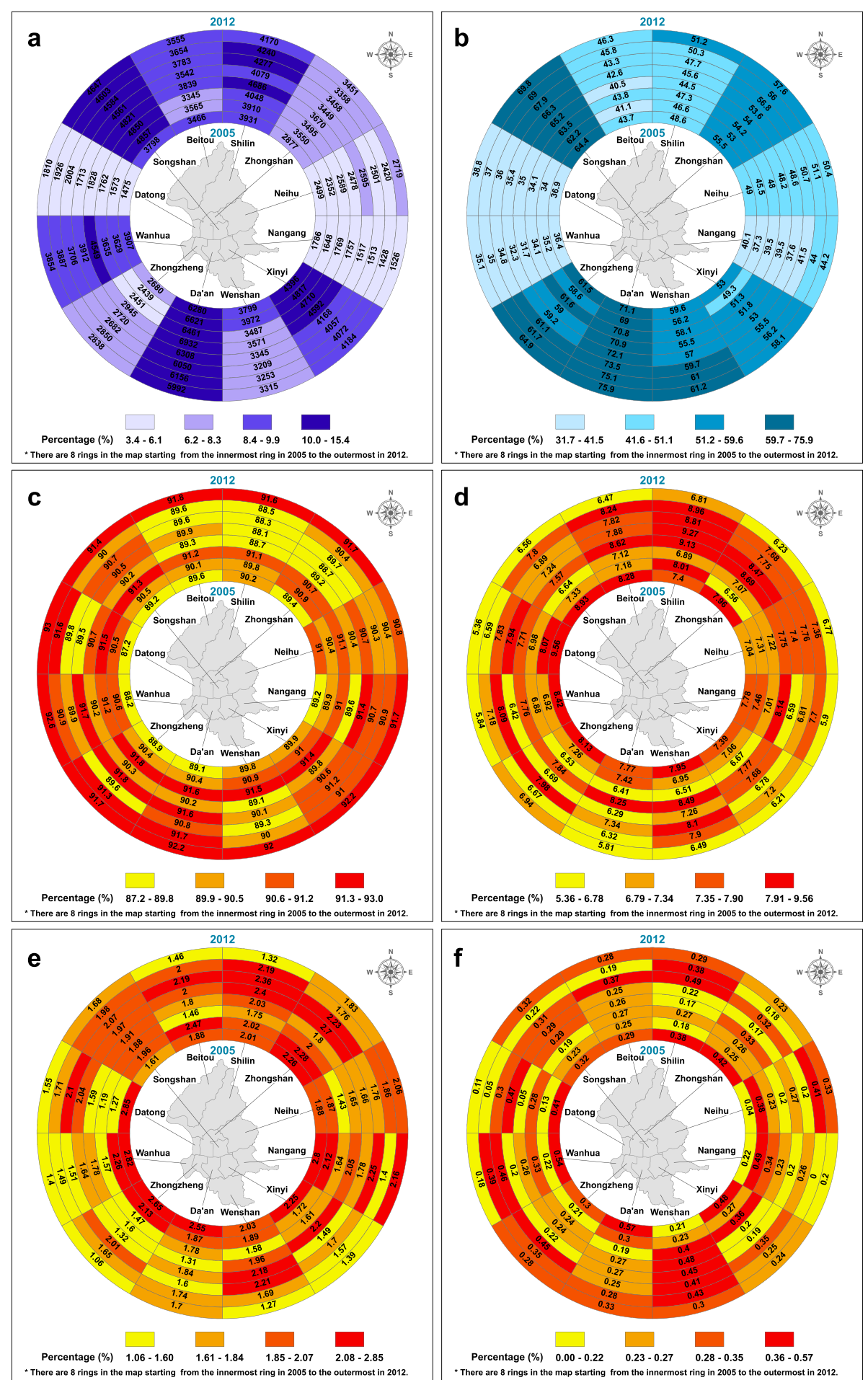

Fig. 3 Health examinations, education and mood disorder among the study population in ring map. a Frequency of elderly health examination from 2005 to 2012 among Taipei residents. The labels in the rings reprsent the number of participants. b Percentage of senior high school and above in Taipei elderly health examination. c Percentage of normal mood status from 2005 to 2012 in Taipei elderly health examination. d Percentage of mild mood disorders from 2005 to 2012 in Taipei elderly health examination. e Percentage of moderate mood disorders from 2005 to 2012 in Taipei elderly health examination. f Percentage of severe mood disorders from 2005 to 2012 in Taipei elderly health examination 
emotional distress problems were found in Da'an, Wenshan, Shilin, Wanhua and Neihu Districts.

Participants' characteristics for the groups with or without mood disorder based on BSRS-5 score are shown in Table 1. Most participants were $70-74$ years old (25.9\%), with elementary school education level (23.6\%), female (52.4\%), drinking milk (52.0\%), eating at least three servings of vegetables and two servings of fruits (77.3\%), taking long-term medication (74.3\%), non-smoking (94.6\%), not drinking alcohol (80.5\%), with BMI within 18.5-23.9 (46.5\%), self-reporting chronic diseases (43.2\%), and not living alone (93.3\%). In our results, all variables were significantly different between groups with and without mood disorders except the number of chronic diseases.

Physical and biochemical values of the study population are summarized in Table 2. The results reveal that the averages of height, weight, diastolic blood pressure, total cholesterol, and triglycerides were statistically significant between groups with and without mood disorder.

People with mood disorders had relatively low height $(157.48$ vs. $158.86 \mathrm{~cm})$, weight $(59.93$ vs. $61.01 \mathrm{~kg})$, and diastolic pressure (74.87 vs. $75.19 \mathrm{mmHg})$, while cholesterol (196.43 vs. $194.42 \mathrm{mg} / \mathrm{dL})$ and triglycerides (121.71 vs. $120.28 \mathrm{mg} / \mathrm{dL}$ ) were relatively high.

The risk factors related to mood disorder are examined with a generalized estimation equation model, and the results are shown in Table 3. People with lower education level, or who were female, divorced, didn't drink milk, didn't eat three servings of vegetables and two servings of fruits, or who were taking long-term medication, reported smoking daily, never had physical activity, or had higher cholesterol were all at higher risk of mood disorders than their counterparts. For example, people with a higher educational level revealed a protective effect (both OR and 95\% CI of university and master's degree or above are less than 1). In terms of gender, males had a very low OR (0.572) compared to females. In marital status, the divorced had a significantly higher OR (1.22) compared to married--living together. As for healthy behaviors, not drinking milk (1.117), not eating three servings of vegetables and two servings of fruits (1.782) and daily smoking (1.152) all had significantly high OR compared to their counterparts. However, people not taking long-term medication (0.571), occasionally drinking (0.955), occasionally exercising (0.955), aged between 80 and 85, and those with fewer chronic diseases had significantly lower risk of mood disorder. Regarding biochemical values, people with higher cholesterol had a higher odds ratio related to mood disorder.

Furthermore, we tried to examine the risk differences between genders. There appeared no risk differences between genders in educational level, milk drinking, vegetables and fruits intake, long-term medication, and cholesterol level, while marital status, smoking and alcohol frequency, exercise frequency, age, and the number of chronic diseases presented mild variations between males and females (Table 4).

\section{Discussion}

This study applied long-term follow-up data on the elderly participating in the Taipei health examination at least twice to analyze the possible risk factors for mood disorders in the elderly. In our study, we collected all potential risk factors from the health examination. In addition to finding out the risk factors from the existing literature, we also tried to examine some new factors from our unique database. Although elderly mental health is an important issue in past studies, this study demonstrated different kinds of potential risk factors together and had multiple repeated measurements to validate the results. We found not only risk factors, but also protective factors for mood disorders in the elderly simultaneously in one study. The results suggest that health policy makers implement behavior intervention to reduce mood disorders with health education. We found that the residents living in districts with a higher average educational level were more willing to participate in the health examination. In addition, we also identified the personal demographic factors, health behaviors and self-report of medication factors associated with mood disorders.

Our results reveal that the demographic variables of female, older age, lower education level, and divorced status are associated with mood disorders. Specifically, previous studies have shown that gender $[28,29]$ and age [30] are associated with depression. The results in the present study are consistent with domestic and international research, which indicated that gender difference also plays a role in mental health [31,32]. For the elderly, our study illustrates that marital status (particularly, divorce) is a key factor associated with mood disorders. One study in Singapore found that females have higher depressive symptom scores than males. However, living alone and weak social networks outside the household were associated with higher depressive symptoms in both males and females [29]. Hence, for the elderly, living alone, not being married [18], and weak social networks may all increase their emotional isolation and social disengagement. They are consequently more likely to have mood disorders. Higher education seems to be a protective factor in the elderly [33]. A previous study showed that higher social activity was associated with a lower risk of late-life depressive symptoms at a baseline in a large community sample with 2 years of follow-up [34]. Another study, in Korea, founded that those who participated in frequent physical, social, and some religious activity had a low odds ratio for depression 
Table 1 Characteristics of elderly adults with and without mood disorder. Values are counts (percentages) unless stated otherwise

\begin{tabular}{|c|c|c|c|c|c|c|c|c|}
\hline \multirow[t]{2}{*}{ Variable } & \multirow[t]{2}{*}{ Total } & & \multicolumn{4}{|c|}{ Mood disorder } & \multirow[t]{2}{*}{$x^{2}$} & \multirow[t]{2}{*}{$p$-value } \\
\hline & & & No & & $\mathrm{Yes}^{\mathrm{a}}$ & & & \\
\hline Age $(n=315,045)$ & & & & & & & 51.74 & .001 \\
\hline $65-69$ & 78,764 & $(25.0)$ & 71,099 & $(22.6)$ & 7665 & $(2.4)$ & & \\
\hline $70-74$ & 81,746 & $(25.9)$ & 73,729 & $(23.4)$ & 8017 & $(2.5)$ & & \\
\hline $75-79$ & 75,425 & $(23.9)$ & 68,253 & $(21.7)$ & 7172 & $(2.3)$ & & \\
\hline $80-84$ & 51,844 & $(16.5)$ & 47,243 & $(15)$ & 4601 & $(1.5)$ & & \\
\hline$>85$ & 27,266 & $(8.7)$ & 24,859 & (7.9) & 2407 & $(0.8)$ & & \\
\hline Education $(n=306,895)$ & & & & & & & 284.40 & .001 \\
\hline Illiterate & 17,036 & (5.4) & 15,116 & $(4.8)$ & 1920 & $(0.6)$ & & \\
\hline Self-taught & 6848 & $(2.2)$ & 6156 & $(2)$ & 692 & $(0.2)$ & & \\
\hline Elementary school & 74,255 & $(23.6)$ & 66,635 & $(21.2)$ & 7620 & $(2.4)$ & & \\
\hline Junior high school & 46,211 & $(14.7)$ & 41,649 & $(13.2)$ & 4562 & $(1.4)$ & & \\
\hline Senior high school & 72,394 & $(23.0)$ & 65,553 & $(20.8)$ & 6841 & $(2.2)$ & & \\
\hline Vocational school & 27,442 & $(8.7)$ & 25,017 & $(7.9)$ & 2425 & $(0.8)$ & & \\
\hline University & 62,709 & $(19.9)$ & 57,517 & $(18.3)$ & 5192 & (1.6) & & \\
\hline Master's degree and above & 8150 & $(2.6)$ & 7540 & $(2.4)$ & 610 & $(0.2)$ & & \\
\hline Gender $(n=315,045)$ & & & & & & & 1285.19 & .001 \\
\hline Male & 149,920 & $(47.6)$ & 132,766 & $(42.1)$ & 17,154 & (5.4) & & \\
\hline Female & 165,125 & $(52.4)$ & 152,417 & $(48.4)$ & 12,708 & (4) & & \\
\hline Marital status $(n=315,045)$ & & & & & & & 144.45 & .001 \\
\hline Unmarried & 14,182 & $(4.5)$ & 12,877 & $(4.1)$ & 1305 & $(0.4)$ & & \\
\hline Cohabitating & 1357 & $(0.4)$ & 1224 & $(0.4)$ & 133 & (0) & & \\
\hline Married-living together & 233,800 & $(74.2)$ & 212,377 & $(67.4)$ & 21,423 & $(6.8)$ & & \\
\hline Married-living separately & 6581 & $(2.1)$ & 5949 & $(1.9)$ & 632 & $(0.2)$ & & \\
\hline Divorced & 4059 & (1.3) & 3634 & $(1.2)$ & 425 & $(0.1)$ & & \\
\hline Widowed & 55,066 & $(17.5)$ & 49,122 & $(15.6)$ & 5944 & $(1.9)$ & & \\
\hline Living alone $(n=315,045)$ & & & & & & & 9.40 & .002 \\
\hline Yes & 20,987 & $(6.7)$ & 18,872 & (6) & 2115 & $(0.7)$ & & \\
\hline No & 294,058 & $(93.3)$ & 266,311 & $(84.5)$ & 27,747 & $(8.8)$ & & \\
\hline Drinking milk $(n=273,621)$ & & & & & & & 146.69 & .001 \\
\hline Yes & 142,323 & $(52.0)$ & 129,510 & $(47.3)$ & 12,813 & $(4.7)$ & & \\
\hline No & 131,298 & $(48.0)$ & 117,680 & $(43.0)$ & 13,618 & $(5.0)$ & & \\
\hline $\begin{array}{l}\text { Eating at least three servings of vegetables } \\
\text { and two of fruits }(n=273,343)\end{array}$ & & & & & & & 1428.72 & .001 \\
\hline Yes & 211,346 & $(77.3)$ & 193,371 & $(70.7)$ & 17,975 & $(6.6)$ & & \\
\hline No & 61,997 & $(22.7)$ & 53,562 & $(19.6)$ & 8435 & $(3.1)$ & & \\
\hline Long-term medication $(n=315,045)$ & & & & & & & 1140.09 & .001 \\
\hline Yes & 234,157 & $(74.3)$ & 209,537 & $(66.5)$ & 24,620 & $(7.8)$ & & \\
\hline No & 80,888 & $(25.7)$ & 75,646 & $(24.0)$ & 5242 & $(1.7)$ & & \\
\hline Smoking status $(n=309,030)$ & & & & & & & 9.66 & .008 \\
\hline Non-smoking & 292,405 & $(94.6)$ & 264,580 & $(85.6)$ & 27,825 & $(9.0)$ & & \\
\hline Daily smoking & 3965 & $(1.3)$ & 3561 & $(1.2)$ & 404 & $(0.1)$ & & \\
\hline Smoking after a meal & 12,660 & $(4.1)$ & 11,547 & $(3.7)$ & 1113 & $(0.4)$ & & \\
\hline Alcohol frequency $(n=314,285)$ & & & & & & & 121.67 & .001 \\
\hline
\end{tabular}


Table 1 Characteristics of elderly adults with and without mood disorder. Values are counts (percentages) unless stated otherwise (Continued)

\begin{tabular}{|c|c|c|c|c|c|c|c|c|}
\hline \multirow[t]{2}{*}{ Variable } & \multirow[t]{2}{*}{ Total } & & \multicolumn{4}{|c|}{ Mood disorder } & \multirow[t]{2}{*}{$x^{2}$} & \multirow[t]{2}{*}{$p$-value } \\
\hline & & & No & & Yes $^{a}$ & & & \\
\hline Non-drinking & 253,083 & $(80.5)$ & 228,385 & $(72.7)$ & 24,698 & (7.9) & & \\
\hline Daily drinking & 6743 & $(2.2)$ & 6166 & $(2.0)$ & 577 & $(0.2)$ & & \\
\hline Occasional drinking & 54,459 & $(17.3)$ & 49,952 & $(15.9)$ & 4507 & $(1.4)$ & & \\
\hline The frequency of physical activity $(n=261,870)$ & & & & & & & 46.38 & .001 \\
\hline Never & 30,683 & $(11.8)$ & 27,531 & $(4.9)$ & 3152 & (6.9) & & \\
\hline Three to five times per week & 142,049 & $(54.2)$ & 129,181 & $(30.7)$ & 12,868 & $(23.5)$ & & \\
\hline Occasionally & 89,138 & (34) & 80,703 & $(16.2)$ & 8435 & (17.8) & & \\
\hline Body Mass Index $(n=313,262)$ & & & & & & & 33.36 & .001 \\
\hline$<18.5$ & 13,006 & $(4.2)$ & 11,733 & (3.7) & 1273 & $(0.4)$ & & \\
\hline $18.5-23.9$ & 145,737 & $(46.5)$ & 131,764 & $(42.1)$ & 13,973 & $(4.5)$ & & \\
\hline $24.0-26.9$ & 98,629 & $(31.5)$ & 89,651 & $(28.6)$ & 8978 & (2.9) & & \\
\hline $27.0-29.9$ & 40,893 & (13) & 36,990 & $(11.8)$ & 3903 & $(1.2)$ & & \\
\hline $30.0-34.9$ & 13,489 & $(4.3)$ & 12,092 & (3.9) & 1397 & $(0.4)$ & & \\
\hline$\geq 35.0$ & 1508 & $(0.5)$ & 1352 & $(0.49)$ & 156 & $(0.01)$ & & \\
\hline Number of chronic diseases $(n=315,018)$ & & & & & & & 15.41 & .118 \\
\hline 0 & 93,010 & (29.5) & 84,423 & (26.8) & 8587 & $(2.7)$ & & \\
\hline 1 & 136,210 & $(43.2)$ & 123,289 & (39.1) & 12,921 & $(4.1)$ & & \\
\hline 2 & 60,962 & (19.4) & 55,014 & $(17.5)$ & 5948 & (1.9) & & \\
\hline 3 & 19,629 & (6.2) & 17,718 & (5.6) & 1911 & (0.6) & & \\
\hline 4 & 4295 & (1.4) & 3891 & $(1.2)$ & 404 & $(0.1)$ & & \\
\hline$\geq 5$ & 912 & (0.3) & 822 & $(0.2)$ & 90 & (0.1) & & \\
\hline
\end{tabular}

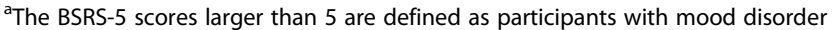

compared with their counterparts [35]. In summary, these elderly with few social network links and/or who are divorced may have high risk of mood disorders because they are lonely and seldom interact with others.

The percentage of elderly people who participated in the health examination in this study who were living in

Table 2 Physical and biochemical values of study population

\begin{tabular}{|c|c|c|c|c|c|}
\hline \multirow[t]{2}{*}{ Variable } & \multirow{2}{*}{$\begin{array}{l}\text { Reference } \\
\text { value }\end{array}$} & \multirow[t]{2}{*}{ Mean } & \multicolumn{2}{|c|}{ Mood Disorder } & \multirow[t]{2}{*}{$p$-value } \\
\hline & & & No & Yes & \\
\hline Height & $--\mathrm{cm}$ & 158.73 & 158.86 & 157.48 & .001 \\
\hline Weight & $--\mathrm{kg}$ & 60.91 & 61.01 & 59.93 & .001 \\
\hline Systolic & $<120 \mathrm{mmHg}$ & 134.61 & 134.62 & 134.44 & .118 \\
\hline Diastolic & $<80 \mathrm{mmHg}$ & 75.16 & 75.19 & 74.87 & .001 \\
\hline Pulse rate & $60-80 / \mathrm{min}$ & 73.15 & 73.15 & 73.20 & .462 \\
\hline Glucose & $70-100$ mg/dL & 104.63 & 104.64 & 104.54 & .515 \\
\hline Cholesterol & $<200 \mathrm{mg} / \mathrm{dL}$ & 194.61 & 194.42 & 196.43 & .001 \\
\hline Triglycerides & $<150 \mathrm{mg} / \mathrm{dL}$ & 120.41 & 120.28 & 121.71 & .001 \\
\hline $\mathrm{GOT}^{*}$ & 8-31 U/L & 24.97 & 24.97 & 24.99 & .795 \\
\hline $\mathrm{GPT}^{*}$ & $0-41 \mathrm{U} / \mathrm{L}$ & 22.51 & 22.52 & 22.44 & .457 \\
\hline
\end{tabular}

*GOT Glutamic Oxaloacetic Transaminase. GPT Glutamic Pyruvic Transaminase
Datong, Nangang and Neihu districts is low. The proportion with a high school education and above in these areas is low as well (less than 50\%). The above results lead us to speculate that education level may affect health risk awareness. People with higher education level are more concerned about their health and willing to conduct regular health examinations [36-38]. In addition, we found that those with lower education levels were more likely to suffer from mood disorders, which was consistent with results of previous studies [30, 39, 40]. Low economic status may be associated with educational opportunity and less chance to access medical service [41]. The worst geographical areas in terms of mood disorders are Wenshan, Shilin and Zhongshan districts. In contrast, the areas with the highest proportion of normal mood status are Nangang, Xinyi, Da'an and Zhongzheng districts. Among them, people in Xinyi and Da'an districts had senior high school education level in a higher proportion than other districts. These areas are important business and economic areas. Therefore, the better mood may be owing to having a better material life for the elderly [42, 43]. In contrast, low education level and economic status may 
Table 3 Risk factors of mood disorder

\begin{tabular}{|c|c|c|c|}
\hline Variable & Beta $(95 \%$ Cl) & $p$-value & OR $(95 \% \mathrm{Cl})$ \\
\hline \multicolumn{4}{|l|}{ Demographic variables } \\
\hline \multicolumn{4}{|l|}{ Education } \\
\hline Master's and above & $-0.129(-0.2$ to -0.06$)$ & .001 & 0.879 (0.82 to 0.95$)$ \\
\hline University & $-0.077(-0.11$ to -0.04$)$ & .001 & 0.926 (0.89 to 0.96$)$ \\
\hline Vocational school & $-0.044(-0.09$ to 0$)$ & .051 & 0.957 (0.92 to 1$)$ \\
\hline Junior high school & $-0.025(-0.06$ to 0.01$)$ & .147 & 0.976 (0.94 to 1.01$)$ \\
\hline Senior high school & $-0.019(-0.06$ to 0.02$)$ & .324 & 0.981 (0.95 to 1.02$)$ \\
\hline Self-taught & $-0.039(-0.12$ to 0.04$)$ & .341 & 0.962 (0.89 to 1.04$)$ \\
\hline Illiterate & 0.025 (-0.03 to 0.08$)$ & .363 & 1.025 (0.97 to 1.08$)$ \\
\hline \multicolumn{4}{|l|}{ Elementary school } \\
\hline \multicolumn{4}{|l|}{ Gender } \\
\hline Male & $-0.559(-0.59$ to -0.53$)$ & .001 & 0.572 (0.56 to 0.59$)$ \\
\hline \multicolumn{4}{|l|}{ Female } \\
\hline \multicolumn{4}{|l|}{ Marital status } \\
\hline Widowed & $0.026(-0.01$ to 0.06$)$ & .125 & 1.027 (0.99 to 1.06$)$ \\
\hline Divorced & 0.199 (0.09 to 0.31$)$ & .001 & $1.22(1.09$ to 1.36$)$ \\
\hline Married--living separately & 0.004 (-0.08 to 0.08$)$ & .931 & 1.004 (0.93 to 1.09$)$ \\
\hline Cohabitating & $-0.107(-0.28$ to 0.07$)$ & .222 & 0.899 (0.76 to 1.07$)$ \\
\hline Unmarried & $-0.027(-0.08$ to 0.03$)$ & .328 & 0.974 (0.92 to 1.03$)$ \\
\hline \multicolumn{4}{|l|}{ Married--living together } \\
\hline \multicolumn{4}{|l|}{ Drinking milk } \\
\hline No & 0.111 (0.09 to 0.13) & .001 & 1.117 (1.09 to 1.14$)$ \\
\hline \multicolumn{4}{|l|}{ Yes } \\
\hline \multicolumn{4}{|c|}{ Eating at least three servings of vegetables and two of fruits } \\
\hline No & 0.578 (0.55 to 0.61$)$ & .001 & $1.782(1.73$ to 1.83$)$ \\
\hline \multicolumn{4}{|l|}{ Yes } \\
\hline \multicolumn{4}{|l|}{ Long-term medication } \\
\hline No & $-0.561(-0.58$ to -0.54$)$ & .001 & 0.571 (0.56 to 0.58$)$ \\
\hline \multicolumn{4}{|l|}{ Yes } \\
\hline \multicolumn{4}{|l|}{ Smoking frequency } \\
\hline Smoking after meals & $-0.034(-0.09$ to 0.02$)$ & .193 & 0.966 (0.92 to 1.02$)$ \\
\hline Daily smoking & $0.142(0.01$ to 0.28$)$ & .041 & $1.152(1.01$ to 1.32$)$ \\
\hline \multicolumn{4}{|l|}{ Non-smoking } \\
\hline \multicolumn{4}{|l|}{ Alcohol frequency } \\
\hline Occasionally drinking & $-0.046(-0.08$ to -0.02$)$ & .002 & 0.955 (0.93 to 0.98$)$ \\
\hline Daily drinking & $-0.067(-0.15$ to 0.01$)$ & .098 & 0.935 (0.86 to 1.01$)$ \\
\hline \multicolumn{4}{|l|}{ Non-drinking } \\
\hline \multicolumn{4}{|l|}{ The frequency of physical activity } \\
\hline Occasionally & $-0.046(-0.09$ to -0.01$)$ & .024 & 0.955 (0.92 to 0.99$)$ \\
\hline Three to five times per week & $-0.059(-0.1$ to -0.02$)$ & .002 & 0.942 (0.91 to 0.98$)$ \\
\hline
\end{tabular}

Never 
Table 3 Risk factors of mood disorder (Continued)

\begin{tabular}{|c|c|c|c|}
\hline Variable & Beta $(95 \% \mathrm{Cl})$ & $p$-value & OR $(95 \% \mathrm{Cl})$ \\
\hline \multicolumn{4}{|l|}{ Age } \\
\hline$>85$ & $-0.032(-0.08$ to 0.01$)$ & .160 & 0.968 (0.93 to 1.01$)$ \\
\hline $80-84$ & $-0.042(-0.08$ to -0.01$)$ & .022 & 0.959 (0.93 to 0.99$)$ \\
\hline $75-79$ & $-0.008(-0.04$ to 0.03$)$ & .650 & 0.993 (0.96 to 1.03 ) \\
\hline $70-74$ & 0.001 ( -0.03 to 0.03$)$ & .940 & 1.001 (0.97 to 1.03 ) \\
\hline \multicolumn{4}{|l|}{$65-69$} \\
\hline Number of chronic diseases & 0.021 (0.01 to 0.03 ) & .002 & $1.02(1.01$ to 1.03$)$ \\
\hline \multicolumn{4}{|l|}{ Biochemical value } \\
\hline Cholesterol & $0.001(0.001-0.001)$ & .014 & $1.00(1.00-1.00)$ \\
\hline
\end{tabular}

elevate life pressure, which may directly or indirectly worsen mood status.

Additionally, lifestyle is the most important factor affecting health [44]. Healthy behaviors, for example, food and alcohol intake, smoking and frequency of physical activity, are included. Our study also revealed the lifestyle characteristics of the elderly that may be associated with mood disorders. We found that drinking milk, as well as eating at least three servings of vegetables and two servings of fruits, is associated with a lower chance of developing mood disorders in the elderly. The present study found that elderly people who had no depressive symptoms were more likely to consume well-balanced meals and milk products on a daily basis [45]. In addition, one study illustrated that adherence to a Mediterranean dietary pattern ensures an adequate intake of fruits, nuts, vegetables, cereals, legumes and fish, all of which are important sources of nutrients linked to lower risk of depression [46]. Another study indicated that intake of milk products is also thought to be related to reduced depressive symptoms among elderly people [47]. Calcium and milk intake is indirectly related to depressive symptoms because it prevents central adiposity, which has been associated with depression [48]. This finding supports current recommendations for increasing milk, fruit and vegetable intake to improve mental health. Moreover, Nakao and Yano (2004) determined that depression is associated with high serum cholesterol levels among middle-aged Japanese men [19]. This is similar to our finding that higher cholesterol levels were associated with mood disorders in the elderly.

On the other hand, unhealthy behaviors, for example, daily smoking, and never exercising, were risk factors of mood disorders. Two previous studies have illustrated that people who smoke or have smoked are more depressed than those who have not done so before, but these findings were significant in only one of the two studies [18, 19]. However, occasionally drinking alcohol has a mild protective effect against mood disorders. This result is also similar to a previous study, which indicated that moderate alcohol consumption in women was related to fewer depressive symptoms in later life [48]. Additionally, previous studies have revealed that leisure activity participation can improve psychological well-being in older adults [49]. Similar to our findings, those suggest that participation in recreational physical activity is associated with a lower chance of developing mood disorders among the elderly. The mental happiness achieved through physical activity enables the elderly to reduce their stress.

Furthermore, poor health status has been demonstrated to be a risk factor for depression in the elderly, such as having a history of stroke, cancer or Parkinson's disease [50, 51]. Patients may feel frustrated because they lose their self-care ability and feel they are troublesome to their families. Among our participants, their self-reported history of medication and chronic disease showed that having more chronic diseases is associated with mood disorders among the elderly.

Previous studies have indicated that there are many risk factors related to depression. From the perspective of preventive medicine, mental health of the elderly in the community is very important. Through community monitoring, risk factors affecting the mood of the elderly can be found, and this will help with follow-up prevention work. Our study has shown that age, education, whether one lives alone, smoking, drinking, vegetable intake, long-term medication and BMI are significantly different in the elderly who have or do not have mood disorders. The results can provide us a micro-level understanding of the differences in mood disorders vis-à-vis the characteristics of elderly people in Taipei.

However, there are some limitations in this study. A major one is that the sample consisted of elderly participants who were willing to take part in the health examination; thus, the sampling was not randomized. The voluntary participants of this study may not be representative of the general population. Our cohort most likely represented a younger and more highly educated 
Table 4 Risk factors of mood disorder of gender

\begin{tabular}{|c|c|c|}
\hline \multirow[t]{2}{*}{ Variables } & \multicolumn{2}{|l|}{ OR $(95 \% \mathrm{Cl})$} \\
\hline & Male & Female \\
\hline \multicolumn{3}{|l|}{ Demographic variables } \\
\hline \multicolumn{3}{|l|}{ Education } \\
\hline Master's and above & $0.893(0.82 \text { to } 0.97)^{*}$ & 0.868 (0.71 to 1.06$)$ \\
\hline University & $0.938(0.9 \text { to } 0.98)^{*}$ & $0.91(0.84 \text { to } 0.98)^{*}$ \\
\hline Vocational school & 0.958 (0.91 to 1.02$)$ & 0.962 (0.88 to 1.05$)$ \\
\hline Junior high school & 0.983 (0.94 to 1.03$)$ & $0.966(0.9$ to 1.03$)$ \\
\hline Senior high school & 1.009 (0.95 to 1.07$)$ & 0.958 (0.9 to 1.03$)$ \\
\hline Self-taught & 0.926 (0.82 to 1.04$)$ & 0.992 (0.93 to 1.06) \\
\hline Illiterate & 1.071 (0.97 to 1.19$)$ & 0.979 (0.87 to 1.1$)$ \\
\hline \multicolumn{3}{|l|}{ Elementary school } \\
\hline \multicolumn{3}{|l|}{ Marital status } \\
\hline Widowed & $1.069(1.01 \text { to } 1.13)^{*}$ & 1.006 (0.97 to 1.05$)$ \\
\hline Divorced & $1.386(1.19 \text { to } 1.61)^{*}$ & 1.063 (0.91 to 1.24$)$ \\
\hline Married--living separately & 1.026 (0.93 to 1.13$)$ & 0.982 (0.86 to 1.12 ) \\
\hline Cohabitating & 0.997 (0.77 to 1.3$)$ & 0.852 (0.68 to 1.07$)$ \\
\hline Unmarried & $1.026(0.96$ to 1.1$)$ & $0.91(0.84 \text { to } 0.99)^{*}$ \\
\hline \multicolumn{3}{|l|}{ Married--living together } \\
\hline \multicolumn{3}{|l|}{ Drinking milk } \\
\hline No & $1.111(1.08 \text { to } 1.14)^{*}$ & $1.125(1.09 \text { to } 1.16)^{*}$ \\
\hline \multicolumn{3}{|l|}{ Yes } \\
\hline \multicolumn{3}{|c|}{ Eating at least three servings of vegetables and two of fruits } \\
\hline No & $1.69(1.63 \text { to } 1.76)^{*}$ & $1.885(1.8 \text { to } 1.97)^{*}$ \\
\hline \multicolumn{3}{|l|}{ Yes } \\
\hline \multicolumn{3}{|l|}{ Long-term medication } \\
\hline No & $0.606(0.59 \text { to } 0.63)^{*}$ & $0.538(0.52 \text { to } 0.56)^{*}$ \\
\hline \multicolumn{3}{|l|}{ Yes } \\
\hline \multicolumn{3}{|l|}{ Smoking frequency } \\
\hline Smoking after meals & 0.981 (0.93 to 1.04$)$ & 0.902 (0.79 to 1.03$)$ \\
\hline Daily smoking & $1.179(1.02 \text { to } 1.37)^{*}$ & $1.026(0.71$ to 1.48$)$ \\
\hline \multicolumn{3}{|l|}{ Non-smoking } \\
\hline \multicolumn{3}{|l|}{ Alcohol frequency } \\
\hline Occasionally drinking & $0.956(0.93 \text { to } 0.99)^{*}$ & 0.956 (0.9 to 1.01$)$ \\
\hline Daily drinking & 0.981 (0.9 to 1.07$)$ & $0.719(0.57 \text { to } 0.91)^{*}$ \\
\hline \multicolumn{3}{|l|}{ Non-drinking } \\
\hline \multicolumn{3}{|l|}{ Frequency of physical activity } \\
\hline Occasional & 0.978 (0.92 to 1.04$)$ & $0.942(0.89$ to 1$)$ \\
\hline Three to five times per week & 0.966 (0.92 to 1.02$)$ & $0.928(0.88 \text { to } 0.98)^{*}$ \\
\hline \multicolumn{3}{|l|}{ Never } \\
\hline \multicolumn{3}{|l|}{ Age } \\
\hline$>85$ & 0.964 (0.91 to 1.02$)$ & 0.98 (0.91 to 1.06$)$ \\
\hline $80-84$ & $0.949(0.91 \text { to } 0.99)^{*}$ & 0.985 (0.93 to 1.05$)$ \\
\hline
\end{tabular}


Table 4 Risk factors of mood disorder of gender (Continued)

\begin{tabular}{lll}
\hline Variables & \multicolumn{1}{l}{ OR (95\% Cl) } & Female \\
\cline { 2 - 3 } & Male & $0.999(0.95$ to 1.05$)$ \\
\hline $75-79$ & $0.988(0.95$ to 1.03$)$ & $0.993(0.95$ to 1.04$)$ \\
$70-74$ & $1.012(0.97$ to 1.06$)$ & $1.029(1.01 \text { to } 1.05)^{*}$ \\
$65-69$ & & $1.008(0.99$ to 1.02$)$ \\
$\begin{array}{l}\text { Number of chronic diseases } \\
\text { Biochemical value } \\
\text { Cholesterol }\end{array}$ & $1(1$ to 1$)$ & $1(1$ to 1$)$ \\
\hline
\end{tabular}

* $p$-value $<0.05$

population, with more people having intact cognitive abilities. We might underestimate the risk from self-selection bias of healthier participants. Second, it was a second-hand dataset containing self-reported information, which may carry some bias, such as recall bias. Another limitation is that we only use BSRS-5 to estimate the outcome. Other measurements or clinical diagnosis could be added for more precise estimation in the future.

\section{Policy indication}

First, the questionnaire of BSRS-5 is an easy and fast tool to evaluate mental disorders. It is easily deployed in community health examination. Our results indicated that social support, for example, marital status, is a significant factor associated with mental disorders. Policy makers should encourage the elderly to participate in social activities and to reduce loneliness and the risk of mental disorders. Third, this study also found that health behaviors including physical activity, drinking milk, eating more vegetables, and quitting smoking are linked to better mental health. Many of these factors can potentially be improved through health education to reduce the risk of mental disorders. Lastly, the more chronic diseases one suffers from, the higher the risk of mental disorders in the elderly, suggesting that the health system needs to control and reduce chronic diseases in the elderly.

\section{Conclusion}

Our study provides a new approach for better understanding of mood disorders among the elderly with data from a long-term follow-up community health examination. Certain values of demographic variables, such as female gender, low education level and divorced; health behaviors of non-intake of milk, non-intake of fruit and vegetables, smoking and never exercising; and individual variables of long-term medication and a greater number of diseases were all associated with mood disorders. The findings of this research provide a macro view for understanding mood disorders as well as a micro view for identifying risk factors of mood disorders in the elderly through health examination. Our study suggests that health policy makers should focus on reducing those risk factors for developing mood disorders among the elderly.

\section{Abbreviations}

95\% Cl: 95\% confidence interval; ANOVA: Analysis of variance; BMI: Body mass index; BSRS-5: 5-item Brief Symptom Rating Scale; GEE: Generalized estimating equations; NHS: National Health Service; OR: Odds ratio;

WHO: World Health Organization

\section{Acknowledgements}

We gratefully thank the Department of Health, Taipei City Government for allowing use of their data for this study.

\section{Funding}

This research was supported by a grant from the Ministry of Science and Technology, Taiwan (MOST-106-2627-M-001-003) and a grant titled

"Multidisciplinary Health Cloud Research Program: Technology Development and Application of Big Health Data" from Academia Sinica. The funders had no role in study design, data collection and analysis, decision to publish, or preparation of the manuscript.

\section{Availability of data and materials}

The raw data are confidential and cannot readily be shared. Researchers need to obtain permission from the Institutional Review Board and apply for access to the data from the Department of Health, Taipei City Government.

\section{Authors' contributions}

TJT and YSW reviewed the literature, and made substantial contributions to the conception and design. YSW and JHT refined the data and performed statistical analysis. YTL contributed the ring maps. YHC helped interpret the results. TJT, ICF and TCC conceptualized and designed the paper, interpreted the results, and drafted the manuscript. All authors have read and approved the final manuscript.

\section{Ethics approval and consent to participate}

This study was approved by the Institutional Review Board (IRB) on Biomedical Science Research, Academia Sinica (AS-IRB02-104182). This study was designed as a retrospective longitudinal cohort study. Every enrolled participant needed to fill out an informed consent form to authorize the Taipei City Government to process health examination data for the research purpose.

\section{Consent for publication}

Not applicable.

\section{Competing interests}

The authors declare that they have no competing interests.

\section{Publisher's Note}

Springer Nature remains neutral with regard to jurisdictional claims in published maps and institutional affiliations. 


\section{Author details}

'Research Center for Humanities and Social Sciences, Academia Sinica, Taipei, Taiwan. ${ }^{2}$ Graduate Institute of Life Sciences, National Defense Medical Center, Taipei, Taiwan. ${ }^{3}$ Institute of Statistical Science, Academia Sinica, Taipei, Taiwan. ${ }^{4}$ Department of Education and Research, Taipei City Hospital, Taipei, Taiwan. ${ }^{5}$ Institute of History and Philology, Academia Sinica, Taipei, Taiwan. ${ }^{6}$ Institute of Public Health, School of Medicine, National Yang-Ming University, Taipei, Taiwan.

\section{Received: 29 November 2018 Accepted: 19 February 2019} Published online: 28 February 2019

\section{References}

1. WHO. Mental health of older adults. 2017. http://www.who.int/news-room/ fact-sheets/detail/mental-health-of-older-adults. Accessed 21 July 2018.

2. Sun WJ, Xu L, Chan WM, Lam TH, Schooling CM. Depressive symptoms and suicide in 56,000 older Chinese: a Hong Kong cohort study. Soc Psychiatry Psychiatr Epidemiol. 2012;47(4):505-14.

3. NHS England. Half of adults aged 55 and over have experienced common mental health problems, say Age UK. 2017. https://www.england.nhs.uk/ 2017/10/half-of-adults-aged-55-and-over-have-experienced-commonmental-health-problems-say-age-ukJ. Accessed 12 Aug 2018.

4. Age Concern England. Improving services and support for older people with mental health problems. 2007. http://www.mentalhealthpromotion. net/resources/improving-services-and-support-for-older-people-with-mentalhealth-problems.pdf. Accessed 12 Aug 2018.

5. Vaid N. Depression in the elderly. InnovAiT. 2015;8(9):555-61.

6. America MH. 2017 State of mental health in America - adult data. 2017. http://www.mentalhealthamerica.net/issues/2017-state-mental-healthamerica-adult-data. Accessed 30 June 2018.

7. Reynolds K, Pietrzak RH, El-Gabalawy R, Mackenzie CS, Sareen J. Prevalence of psychiatric disorders in U.S. older adults: findings from a nationally representative survey. World Psychiatry. 2015;14(1):74-81.

8. Andreas S, Schulz H, Volkert J, Dehoust M, Sehner S, Suling A, et al. Prevalence of mental disorders in elderly people: the European MentDis_ ICF65+ study. Br J Psychiatry. 2017;210(2):125-31.

9. Demyttenaere K, Bruffaerts R, Posada-Villa J, Gasquet I, Kovess V, Lepine JP, et al. Prevalence, severity, and unmet need for treatment of mental disorders in the World Health Organization world mental health surveys. JAMA. 2004;291(21):2581-90.

10. Amagasa S, Fukushima N, Kikuchi H, Oka K, Takamiya T, Odagiri Y, et al. Types of social participation and psychological distress in Japanese older adults: a five-year cohort study. PLoS One. 2017;12(4):e0175392.

11. Meng X, D'Arcy C. Common and unique risk factors and comorbidity for 12month mood and anxiety disorders among Canadians. Can J Psychiatr. 2012;57(8):479-87.

12. Weyerer S, Eifflaender-Gorfer S, Kohler L, Jessen F, Maier W, Fuchs A, et al. Prevalence and risk factors for depression in non-demented primary care attenders aged 75 years and older. J Affect Disord. 2008;111(2-3):153-63.

13. Inoue S, Ohya Y, Odagiri Y, Takamiya T, Kamada M, Okada S, et al. Perceived neighborhood environment and walking for specific purposes among elderly Japanese. J Epidemiol. 2011;21(6):481-90.

14. Reddy MS. Depression: the disorder and the burden. Indian J Psychol Med. 2010;32(1):1-2.

15. Chang M, Snaedal J, Einarsson B, et al. The association between midlife physical activity and depressive symptoms in late life: age gene/ environment susceptibility—Reykjavik study. J Gerontol A Biol Sci Med Sci. 2016;71:502-7.

16. Ku PW, Fox KR, Chen $\amalg$, Chou P. Physical activity and depressive symptoms in older adults: 11-year follow-up. Am J Prev Med. 2012;42:355-62.

17. Ku PW, Steptoe A, Liao Y, Sun WJ, Chen LJ. Prospective relationship between objectively measured light physical activity and depressive symptoms in later life. Int J Geriatr Psychiatry 2017; https://doi.org/10.1002/ gps.4672. [Epub ahead of print].

18. Li N, Pang L, Chen G, Song X, Zhang J, Zheng X. Risk factors for depression in older adults in Beijing. Can J Psychiatr. 2011;56(8):466-73.

19. Nakao M, Yano E. Relationship between major depression and high serum cholesterol in Japanese men. Tohoku J Exp Med. 2004;204(4):273-87.

20. de Girolamo G, Dagani J, Purcell R, Cocchi A, McGorry PD. Age of onset of mental disorders and use of mental health services: needs, opportunities and obstacles. Epidemiol Psychiatr Sci. 2012;21(1):47-57.
21. Sarris J, O'Neil A, Coulson CE, Schweitzer I, Berk M. Lifestyle medicine for depression. BMC Psychiatry. 2014;14:107.

22. Lung FW, Lee MB. The five-item brief-symptom rating scale as a suicide ideation screening instrument for psychiatric inpatients and community residents. BMC Psychiatry. 2008;8:53.

23. Chen YC, Weng SC, Liu JS, Chuang HL, Hsu CC, Tarng DC. Severe decline of estimated glomerular filtration rate associates with progressive cognitive deterioration in the elderly: a community-based cohort study. Sci Rep. 2017; 7:42690.

24. Hung GC, Kwok CL, Yip PS, Gunnell D, Chen YY. Predicting suicide in older adults -- a community-based cohort study in Taipei City. Taiwan J Affect Disord. 2015;172:165-70.

25. Wu CY, Hu HY, Chou YJ, Huang N, Chou YC, Lee MS, et al. High serum uric acid levels are associated with all-cause and cardiovascular, but not cancer, mortality in elderly adults. J Am Geriatr Soc. 2015;63(9):1829-36.

26. Chan TC, Wang CM, Lee YM. Looking at temporal changes--use this python tool for creating ring maps. ArcUser. 2013:1-3.

27. Touloumis A, Agresti A, Kateri M. GEE for multinomial responses using a local odds ratios parameterization. Biometrics. 2013;69(3):633-40.

28. Luppa M, Sikorski C, Luck T, Ehreke L, Konnopka A, Wiese B, et al. Age- and gender-specific prevalence of depression in latest-life--systematic review and meta-analysis. J Affect Disord. 2012;136(3):212-21.

29. Chan A, Malhotra C, Malhotra R, Ostbye T. Living arrangements, social networks and depressive symptoms among older men and women in Singapore. Int J Geriatr Psychiatry. 2011;26(6):630-9.

30. Sengupta P, Benjamin Al. Prevalence of depression and associated risk factors among the elderly in urban and rural field practice areas of a tertiary care institution in Ludhiana. Indian J Public Health. 2015;59(1):3-8.

31. Campos AC, Ferreira e Ferreira E, Vargas AM, Albala C. Aging, Gender and Quality of Life (AGEQOL) study: factors associated with good quality of life in older Brazilian community-dwelling adults. Health Qual Life Outcomes. 2014;12:166.

32. Chen PL, Tsai $Y L$, Lin MH, Wang J. Gender differences in health promotion behaviors and quality of life among community-dwelling elderly. J Women Aging. 2018;30(3):259-74.

33. Fiske A, Wetherell JL, Gatz M. Depression in older adults. Annu Rev Clin Psychol. 2009:5:363-89.

34. Isaac V, Stewart R, Artero S, Ancelin ML, Ritchie K. Social activity and improvement in depressive symptoms in older people: a prospective community cohort study. Am J Geriatr Psychiatry. 2009;17:688-96.

35. Roh HW, Hong $\mathrm{CH}$, LeeY, et al. Participation in physical, social, and religious activity and risk of depression in the elderly: a community-based three-year longitudinal study in Korea. PLoS One. 2015;10:e0132838.

36. Samouda H, Ruiz-Castell M, Bocquet V, Kuemmerle A, Chioti A, Dadoun F, et al. Geographical variation of overweight, obesity and related risk factors: findings from the European health examination survey in Luxembourg, 2013-2015. PLoS One. 2018;13(6):e0197021.

37. Tchicaya A, Lorentz N. Socioeconomic inequality and obesity prevalence trends in Luxembourg, 1995-2007. BMC Res Notes. 2012;5:467.

38. Yuan F, Qian D, Huang C, Tian M, Xiang Y, He Z, et al. Analysis of awareness of health knowledge among rural residents in Western China. BMC Public Health. 2015;15:55.

39. Assil SM, Zeidan ZA. Prevalence of depression and associated factors among elderly Sudanese: a household survey in Khartoum state. East Mediterr Health J. 2013;19(5):435-40.

40. Simkhada R, Wasti SP, Gc VS, Lee ACK. Prevalence of depressive symptoms and its associated factors in older adults: a cross-sectional study in Kathmandu. Nepal Aging Ment Health. 2018;22(6):802-7.

41. Alexopoulos GS. Depression in the elderly. Lancet. 2005;365(9475):1961-70.

42. Lorant V, Deliege D, Eaton W, Robert A, Philippot P, Ansseau M. Socioeconomic inequalities in depression: a meta-analysis. Am J Epidemiol. 2003;157(2):98-112.

43. Stathi A, Fox KR, McKenna J. Physical activity and dimensions of subjective well-being in older adults. J Aging Phys Act. 2002;10(1):76-92.

44. Lalonde M. A new perspective on the health of Canadians. Ottawa: ON: Minister of Supply and Services Canada; 1974.

45. Saghafian F, Malmir H, Saneei P, Milajerdi A, Larijani B, Esmaillzadeh A. Fruit and vegetable consumption and risk of depression: accumulative evidence from an updated systematic review and meta-analysis of epidemiological studies. Br J Nutr. 2018;119(10):1087-101.

46. Sánchez-Villegas A, Henríquez P, Bes-Rastrollo M, Doreste J. Mediterranean diet and depression. Public Health Nutr. 2006;9(8A):1104-9. 
47. Aihara Y, Minai J, Aoyama A, Shimanouchi S. Depressive symptoms and past lifestyle among Japanese elderly people. Community Ment Health J. 2011; 47(2):186-93.

48. Azadbakht L, Esmaillzadeh A. Dietary and non-dietary determinants of central adiposity among Tehrani women. Public Health Nutr. 2008;11(5): 528-34.

49. Lee $H Y, Y u C P, W u C D$, Pan WC. The effect of leisure activity diversity and exercise time on the prevention of depression in the middle-aged and elderly residents of Taiwan. Int J Environ Res Public Health. 2018;15(4):654. https://doi.org/10.3390/ijerph15040654.

50. Sapranaviciute-Zabazlajeva L, Reklaitiene R, Tamosiunas A, Baceviciene M, Virviciute D, Peasey A. Correlates of depressive symptoms in urban middleaged and elderly Lithuanians. Soc Psychiatry Psychiatr Epidemiol. 2014;49(8): 1199-207.

51. Liu Q, Cai H, Yang LH, Xiang YB, Yang G, Li H, et al. Depressive symptoms and their association with social determinants and chronic diseases in middle-aged and elderly Chinese people. Sci Rep. 2018;8(1):3841.

Ready to submit your research? Choose BMC and benefit from:

- fast, convenient online submission

- thorough peer review by experienced researchers in your field

- rapid publication on acceptance

- support for research data, including large and complex data types

- gold Open Access which fosters wider collaboration and increased citations

- maximum visibility for your research: over $100 \mathrm{M}$ website views per year

At $\mathrm{BMC}$, research is always in progress.

Learn more biomedcentral.com/submissions 